\title{
Roles and Obligations of Individual States Towards Migrating Children and Youth: An African Ethics of Hospitality and Responsibility
}

\section{Muko Cyril Keba \\ ORCID iD: https://orcid.org/0000-0001-8591-5055}

\begin{abstract}
This article reflects on the human crisis of recent waves of forced, sometimes deliberate, mass movements of migrants from Africa converging in Western countries. The movements have sometimes caused hosts of casualties, imprisonments, and the dehumanisation of migrants. All this happens despite the common humanity evidently shared and experienced by all rational creatures living in the common space that is known as mother earth given to the care of the entire human race. I see a fundamental discrepancy between the concern for global warming and the seeming lack of a global front to curb the crisis of migration. While it is one thing to laud the global concern for the common humanity of rational beings as one people living on the one and irreplaceable earth, to-be-cared for by all, it is quite another to interrogate the hesitancy for the global front needed to face migration crisis, of children and youth in particular. The current country-by-country devised solutions lead to the rejection and hostility towards children and youth migrating from different parts of the global village. From this background I argue that an African ethics of hospitality and an ethics of responsibility can form an effective foundation of the roles and obligations of individual countries in the fair management of migration of children and youth who as an alternative to the ageing challenges in many countries.
\end{abstract}

Keywords: migration, crisis, children and youth, ethics of hospitality, ethics of responsibility. 


\section{Introduction}

The debate on migration is a global phenomenon which no nation in the world can escape either as a sending country or as a country receiving migrants (ToroMorn, Maura, \& Alicea 2004). In all this, what is global is not only the migration phenomenon itself, understood and often misunderstood, talked about everywhere, but solutions and strategies predicted to solve this thorny problem are far from being global. Countries often create solutions and strategies that are not strategies to rationalise and humanise migrations, but are often strategies to prevent migrants from approaching countries' borders, thus criminalising migrants (Bacon 2008).

From the foregoing, it can be noted that, in addition to the traditional causes of migration, such as civil wars, political instabilities and economic hardships (Baker et al. 1995; Crush 2001), natural disasters resulting from climate change are increasingly causing peoples' movements (Waldinger \& Fankhauser 2015). In different parts of the world, peoples suffer from natural disasters and feel cut off from any normal life in their natural environment or country of origin; their best option seems to be migration. For White (2011:13) contesting the sense of natural disasters as a valid reason for migration ask:

... does climate change force people to cross international borders in unprecedented numbers? If so, should 'climate migrants' or 'environmental refugees' or 'climate refugees' be understood differently from economic migrants or political refugees? Should they be allowed to cross a secure border and benefit from protection? Or should they be apprehended, detained and repatriated to their country of origin?

From these questions it may be suggested that in the same way that the whole world is concerned about solving the global challenges of climate change, it would be sensible to reflect on the issues of migration in order to provide global solutions that would take into account particular and individual situations by including them in overall strategies.

Within academia, different scholars have examined the African migration phenomenon in various perspectives. For example, Kane and Leedy (2013) looked at the African migrations by considering the patterns of African migrations and they proposed possible perspectives for the solution to the thorny migration crises in Africa. These authors suggested, among other 
solutions, that efforts should be made to resolve the economic hardships that force young people to migrate. On the same topic, Adepoju (2000), reflected on the dynamics that forge the intra-regional migration, emphasising the dynamics that build regional integration in sub-Saharan Africa. Other scholars such as Flahaux and De Haas (2016), have contributed to this debate on African migrations specifying certain identifiable trends, patterns and forces that activate such migrations. For these scholars, the assumptions on African migrations are based on stereotypes rather than on scientific empirical studies. According to Flahaux Marie-Laurence and Hein De Haas (2016: 1), it is stereotyped that African migration is high and increasing, mainly directed towards Europe and driven by poverty and violence. Moving away from such stereotypes, the authors stamp migrations as a mark of people's aspirations and capabilities to migrate whenever they aspire to do so.

From the above thoughts, I argue that the issue of migration must be tackled globally, and efforts not spared, to promote comprehensive strategies and solutions that would treat this problem with humanity, rationality and realism. It is not enough to adopt measures of prevention and closure of borders, because such strategies benefit criminal human traffickers. It is with this foundation that this reflection proposes an ethical reflection that will frame and accompany all migration management strategies.

From a theoretical foundation of ethical analysis, the reflection will be constructed upon a methodology of the critical analysis of the assumptions, principles and procedures (Creswell \& Poth 2016) related to the migration phenomenon. Based on this qualitative approach, the article starts from a comparison of how the world cares and develops universal strategies for resolving the challenges of climate change, and the phenomenon of migration which, being global, is neglected with regard to finding solutions and creating strategies. Then follows a critical analysis of the paradox between the necessity and even, obligation of protection of the borders on the one hand, and on the other hand a humanitarian appeal regarding migrants. It is from this sense of humanity always present in each of the immigrants, that arises a foundation of an ethics of hospitality and responsibility with the approach of rights to migration.

\section{The Phenomenon of Migration is as Global as the Reality of Global Warming}

Many thinkers of modern times agree that migration is essentially a reality of 
human life (Toro-Morn, Maura, \& Alicea 2004; Braasch 2009). It is as global as is the reality of global warming. It has become common knowledge that, deforestation in the center of the equatorial forest of central Africa may affect people in other parts of the world. Plastic bags thrown in drainage systems of any cities in the world will eventually end up in oceans damaging the ecosystem with unimaginable consequences for the 7 billion inhabitants of the world. This is as clear as crystal. What can be deduced from this fact is the assumption that global warming is one of those universal realities and situations that have awakened the sense of common responsibility over the shared planet earth.

In as much as the phenomenon of migration affects every country of the world, in one way or another, it becomes as global as the reality of global warming, for which many summits have been held in search of sustainable answers, e.g., Asia Pacific Climate Week, Youth Climate Week, and, Climate Action Summit (United Nations 2019). The frequency of these summits on climate change underlies the truth of a common concern for the well-being of all humans and other inhabitants of the earth (Afzal 2007). Global warming affects not only countries most advanced in technologies, in development, and in the domination of nature. It impacts life at different layers, even in the least developed countries, still struggling with providing the basic needs of life.

All over the world, leaders of nations, social and political activists agree to collaborate in response to the devastating effects of climate change. They care for even for the most remote places in the world where the ecosystems vary in forms and contribution to the natural maintenance and sustenance of the environment which guarantees a well-balanced life of different beings. Such common concerns also explain the openness in denouncing the participation of individual states in creating the problem, thus defining as close as possible the various levels of responsibilities, and costs to bear by the many culprits. Though, still theoretical, and still lacking universally accepted legal mechanisms to reinforce preventive measures and the recovery of monies from the fines of culprit states, the work and the fight against climate change is no longer the activity of private organisations or environmental activists (Victor 2011). Globally, political, religious, and civic leaders, including children and youth are not short of initiatives to save mother earth. Few states and their leaders remain nonetheless unmoved by the urgency of interventions against global warming which carries historical, political and economic dimensions affecting the different people, communities and nations, 
plants and animals of the world. It breaks and shakes the foundation and boundaries of their lives (Braasch 2009).

The same can be said of migration and immigration whose historical, political and economic impacts affect all people, involved in both, the sending and receiving nations (Toro-Morn, Maura, \& Alicea 2004). As noted, these two phenomena do not spare any part of the world. They are a reality in which the isolation or withdrawal of some nations, or the lack of interest or concerns by other nations cannot benefit them or others. The scourge of these two phenomena is immense, and their consequences are devastating. As such, they may constitute a common source of concern for all nations of the world, globally.

Regrettably, my observation is that while most countries around the world agree to solve the problem of climate change with concerted and strategic efforts, the migration and immigration situation does not attract the general and common interest of most nations. Even though migration is recognised as a global phenomenon, it is nevertheless treated as a scourge of underdeveloped countries, menacing the peace and stability of Western nations and North America. In this perspective, efforts are not spared to stop migration from the sending countries.

This reflection contends that if leaders of the world and most environmental activists are commonly, though diversely concerned by the effects of global warming, and thus formulate global solutions to curb the scourge, it should be reasonable that the phenomenon of migration and immigration must not constitute a source of division between the sending and receiving nations. Just as with global warming, historical, political, and economic impacts of migration tie together the nations of the world. Migration within Africa affects each African country, as it affects other countries outside the continent which might observe the increase of social instability where states shine from the sense of hospitality and responsibility towards migrants. Sometimes, the unwelcomed and wandering migrants try to settle and occupy 'empty' spaces in western cities, creating social conflict with local residents. In the same way, migration from Africa or other less developed nations, to Western countries diversely affect all parties, politically, economically and historically. If this is correct, it calls for a global response to the situation of migration which should be recognised as a global problem.

As an attempt to respond to this fundamental problem, this paper argues that as far as the commonality of earth is concerned, certain universal realities and situations that affect its essential well-being should awaken the 
sense of political responsibility over ways and means of protecting the lifespan of our common inheritance, the earth. Such responsibilities are not only political, but mostly should be founded in people's attitudes and behaviors towards the earth and its inhabitants, in a word, such responsibility must be an ethics. In the line of this reasoning, it will be argued that on the one hand, migration of children and youth commands by its very nature ethical responsibilities of individual states constitutive of the shared earth, and on the other hand, the same states have the political and legal responsibilities to defend and protect their national borders. This is the preamble to the existence of a paradox between recognition of national sovereignties, the obligation for the protection of national borders, and the fundamental demand for the protection of humanity in migrants.

\section{Face to Face with the Paradox of Protection of National Borders' Sovereignty and Preservation of Humanity}

In the face of massive movements of migrants, it can be asked if the sovereignty of national borders matter (Helliwell 2000). Nations of the world as organised and governed, emphasise the importance of borders in matters of economy and trade, politics and international relations, jobs and employment. To this list is added the matter of migration. Borders and migration underlie a topical debate in terms of how national borders affect the fluidity of migration, both internally and internationally (Helliwell 2000: 79). For national security reasons, countries protect their borders, and work within national and international legal frameworks to ensure the respect of their sovereignty as a nation. Observance by all parties has always ensured the empirical success of the sovereignty of others, beneficial trade flows, peaceful and amicable political relationships. Economic growth can also depend on how boundaries of nations are organised and managed. National boundaries are in part determinant of trade flows, investment sustainability, controlled migration, and economic development. For this reason, economic theory on trade relations and national security policy of a country are a result of the conception of borders' reflection of the sovereignty of a country (Helliwell 2000).

In as much as borders matter in economic growth, trade, exchange of information, lateral and bilateral relations, a debate separates protagonists and challengers of closed, soft and open borders (Gibney 1988; Smith 2011). Many countries recognise themselves as those who defend the existence of closed 
borders in such a way that states organise their sovereignty according to national and international laws. They believe that it is the privilege of nationals to make the best use of resources from their territory, and in this way any other foreign citizen, and all other nations share these resources only after having fulfilled all the necessary conditions. On the other hand, others believe that existing frontiers do not promote economic, political and other exchanges; as a result, they claim open borders for trade and other purposes without many restrictions, as in the closed borders (Whelan 1988). Some countries have already achieved openness of borders, such as the countries of the European Union.

It is precisely in the confrontation of these two visions of the borders' policies that I place the existence of the paradox between the sovereignty of the nations (their obligation to protect their borders, to prevent potentially harmful immigrants from entering the country), and the rational demands of the defenders of open borders. Such demands find justification on the need for humanitarian consideration, social justice, ethical and legal obligations to people in need whose lives seem threatened by hunger, wars, natural disasters and other difficulties. The present paradoxicality is articulated in the following ways: First, there are obligations imposed by the implications of national sovereignties, which, by their very nature, demand from the leaders a kind of secureness towards the non-citizens who want to gain access to the national borders. Secondly, National laws, supported by international conventions, oblige political leaders to take actions so that no unauthorised person may end up in the nation, for one reason or another.

The paradox appears clearly in the recent situation of migrations in various parts of the world. How does one reconcile the need for countries to protect their borders against the massive arrival of citizens from other nations, and the humanity-based demands to protect the lives of such wandering citizens of failed states, ungoverned states, or states tangled in civil wars, or ravaged by hunger, natural disasters and poverty?

In recent years, parts of central Africa experienced civil unrests mostly attributed to political power wrangles through undemocratic means (Naido 2013; Lemarchand 2009; Turner 2007; Walker 2017). Parts of West and North Africa encountered unprecedented popular revolutions known as the 'Arab Spring' (Alaoui 2019; Rand 2013). Other troubled regions of the world in the Middle East and Syria threw into the seas and deserts waves of migrants ascending on the 'peaceful' Western countries. These various issues could be 
attributed to years of oppression of people, mismanagement of national resources, corruption, ruthless military rule, lack of democracy, extreme and unethical capitalism or, natural disasters. The same issues have contributed to the acceleration of poverty, insecurity, instability and massive waves of migration of people of all ages. Among them, many children and youth have sought refuge in seemingly peaceful places within Africa and abroad. Wherever the influx of these distressed people has reached, the welcoming has been less than amicable, sometimes, violent, and often based on rejection.

The activists who claim the open admission through borders reject the dramatic restrictions that the defenders of closed borders impose on the citizens of other nations, economies foreign to their own, and without taking into account aspects of proximities with other nations. Closed borders restrict freedom of movement, rendering migration impossible (Whelan 1988:3-39). Closed borders equally disregard all historical relationships (as in the case of colonised countries which have historical ties with former ruling colonial nations). The strategy of constructions of wall fences around countries justified by rationalisation of trade, migration and service delivery, seems less successful, but yet more countries embark on using this strategy. Meanwhile proponents of open borders strategise around the unity of nations, expansion of trade, and renewal of the labor force.

The greatest demand for open borders is justified by the need for freedom of movement of people and material goods on both sides of borders. Any restriction then appears as a violation of these individual freedoms: freedom of movement, freedom to choose a place of residence, freedom to seek the best in a country that offers more opportunities than one's own country of origin (Gibney 1988: 3; Kukathas 2010).

To recognise the fundamental necessity for the freedom of movement and the liberty of people to choose another place of existence when life conditions force them to migrate, presupposes a realisation of the humanitarian morality which necessitates the indisputable right of passage across the borders. It is only by drawing to an end the implications of this right freedom of movement and assuming the very meaning of the lived and experienced humanity in each person that individuals and states on every sides of the borders can realise the need for new conduct and a new way of actions, that of welcoming migrants. Such a new way of action is necessarily a question of ethics.

By this, it is understood the need for any ethical resonance to safeguard the integrity of human life above all other considerations. When human 
existence is in peril, threatened by various situations that force children and youth to migrate, it requires that other humans go beyond legal provisions in order to safeguard the humanity of others, within the ethical dimension of hospitality.

\section{The African Ethics of Hospitality in the Global Administration of Child and Youth Migration}

Jacques Derrida, a great theorist of hospitality warns against any tendency to define hospitality. In his words, 'We do not know what hospitality is', for the reason that it 'rebels against any self-identity, or any consistent, stable, and objectifiable conceptual determination' (Derrida 2000: 6). This is because to Derrida, hospitality is sometimes troubled by its uninvited guest, hostility. I do not intend to unpack Derrida's claim. However, I agree with Derrida that hospitality is ethics (Derrida 2000: 16-17) as it determines a practice of being and acting ways that are either right or wrong. As ethics, hospitality can be both, challenging and practical when it comes to migration; it cannot be short of serious implications in the handling of migrants.

In the same line of thought, Dan Bulley, established the existence of a constitutive link between ethics, power and space with regard the practices of hospitality. He noted that hospitality

operates to form relations between self and other, inside and outside, inclusion and exclusion, those distinctions also need to be policed, managed and controlled, even after the threshold of the home is crossed. Such management and administration of hospitality takes us beyond sovereign mastery and its statist implications (Bulley 2015: 25).

It is this understanding of hospitality that I situate in the African context to better articulate its implications in matters of migration.

Hospitality is a core concept in African ethics (Wiredu 1995; Wiredu \& Gyekye 1992; Nussbaum 2003; Aihiokhai 2017). In the context of African ethics, hospitality is a virtue that seems best shared in African cultures and traditions to the extent that hospitality becomes a conduct, a mode of being, a technique of acting and a way of thinking with respect and accepting the foreign person not as an intruder, but simply as a new-comer. It is a way of being of individuals in the community, and a collective way also. Thus, the 
way of being of the community is defined by the quality of the hospitality towards the newcomer, the visitor, the foreigner. The 'I am' of an African is better defined when 'I' recognise myself in the visitor, the newcomer, who, despite his/her intentions and motives, is at first sight another self-'I am', which must be received without hindrance and prejudices.

This mode of being with respect to the newcomer, determines the mode of conduct to be displayed in front of the stranger. In this perspective, hospitality is simply an ethics of life. In African ethics, an action qualifies as right or wrong in as much as it contributes to the advancement of community or not (Shutte 2009: 94). The African understanding of hospitality carries this same ethics of the advancement of community in the sense that, the newcomer is appreciated and received as an addition to the community. It is this sense of ethics that is in effect in the behaviors of receivers. The individual and collective conduct of members of societies, whether smaller or extended, will be considered morally acceptable insofar as they accept and integrate newcomers into the community. It must be said that foreigners are received as with a clean slate, without suspicion of malice or bad intentions on their part. It is this kind of 'welcoming naivety' that characterises the ethics of African hospitality. This 'naivety' ceases to exist when newcomers exhibit behaviors contrary to the well-being of the community.

As such, this form of ethics can inspire other cultures dealing with the phenomenon of migrations of children and youth. These people can be viewed as newcomers to societies and communities, regardless of their origins and regardless of their motives and intentions. The African ethics of hospitality works in a dialectic of hostility and hospitality. This is to say that, despite the initial fear instilled by the newcomers, because of their difference (language, origin, intentions, motives, appearances), and because of the possibility of threats that their presence may create, African societies, because of their embrace of the ethics of hospitality resorbs this real possibility of hostility by focusing on the virtues and values of hospitality: the acceptance of the other despite the differences, the sense of security provided and promised, the well being of the community.

Thus, the dialectic of hostility and hospitality can move societies in the direction of acceptance of migrants. Hospitality cannot be discarded in a globalised world (Kearney \& Semonovitch 2011). In a world where one must necessarily meet the other, or the interaction and interactivity are correlated in the face of interpersonal relations, one is called upon to substantially re- 
evaluate one's own sense of the other in an atmosphere of multidimensional hospitality, especially hospitality to new-comers or migrants. This form of hospitality can be likened to the ethical dimension of the otherness presented by Emmanuel Levinas (Levinas 1987: 74). In this sense, we must admit that hospitality is always possible even in countries that boast of stiff laws in matters of immigration. Hospitality in the sense of openness to the 'otherness', acceptance of the other as an addition to the human resources of society. Such hospitality is always and already possible. Some nations of the world have demonstrated that it is possible to create conditions of hospitality that escapes from hostility for thousands of newcomers. A case in point is that of Germany's Angela Merkel. In early September 2015, the German Chancellor, amid criticisms from far-right politicians, decided to open the country's borders to migrants from Syria (De La Baume 2017). By this act, the chancellor partially prevented the humanitarian crisis in Europe. While so doing, other countries, such as Hungary and Austria closed their borders, focusing on hostility and imaginary or potential threats and refusing to face the humanity-based needs of the migrants (De La Baume). With the policy of hostility, migrants face a host of casualties, imprisonment, rejection, discriminations, enslavement, alienation and dehumanisation by reason of being labelled illegal immigrants. The German Chancellor remained determined and assured her compatriots and others with a sentence, often, misquoted, many times misunderstood, and sometimes criticised: 'we have already done so much, we will get there this time too' (De La Baume 2017). Did Angela Merkel have a choice? In my view, she did. She had various choices: She could have closed Germany's borders, and ignored the needs of migrants. For example, in the balance of the dialectic between hostility and hospitality, the Chancellor could have leaned towards possible threats posed by the new-comers, and so following suit of other countries, she would have closed German borders to migrants. Instead, she chose the ethical path of hospitality. Between hostility and hospitality, Merkel opted for the latter while Austria, Hungary, Italy, and many other countries focused on hostility and closed their borders, sometimes imprisoning those who tried to gain access through various means and ways (De La Baume 2017).

The issue of children and youth migrants can be resolved when hospitality becomes an alternative to laws of rejection, fears of cultural assimilation and, ideologies of border protectionism. Factors that trigger an influx of migrants always place them 'on edge', which is a place of uncomfortable existence or a non-place of existence or still, a place of non- 
human-existence. The ethics of hospitality indicates that every nation of the world must consider such edges as thresholds at which there is a binding principle, that of the ethics of hospitality that would force countries to open borders and act with humanity towards migrants.

Such biding principles of ethics need to be embodied in international laws that impose to countries an obligation of hospitality as a better way of handling migration. Other scholars admit that,

these laws or conditions are not only legal or customary; they reflect the requirement that events of hospitality occur in circumstances of edge. By this I mean primarily spatial edges - those that obtain at the door, at the gate, on the border (Casey 2011: 39).

Countries must meet the 'newcomers', the migrants, the neighbours at their borders. It is incumbent on the first respondents (authorised representatives of the governments, border guards or patrols, custom officials, police, military personnel, immigration activists) to 'meet' newcomers within the confines of the legal framework guided by the ethics and 'laws' of hospitality.

'To meet' means an encounter of newcomers with words and actions tending to create hospitable steps towards entry into closed spaces or borders. It also means anything but brutality, rejection, imprisonment, insults, criminalisation of migrants by the mere fact of trying to start a life in places of new opportunities. Further, 'to meet' should mean several things: the death of hostility, thresholds where hostility runs out; the space in which hospitality actually happens, whether this be at a border post or on the sea in a makeshift vessel. Finally, 'to meet' means hospitality as occurring in the space of hope as a transforming phenomenon, a matter of beginnings in new human sociality through which significant interconnectivity, in the sense of care, recognition and acceptance transpire. In such an active hermeneutic, to 'meet' can only be effective in the possibility of a global solidarity and all-encompassing responsibility. Such solidarity is self-evidently an ethics of responsibility which is also a self-commitment to fulfil one's part in the conduct of hospitality.

\section{The Ethics of Responsibility: It Takes a Village to Raise a Child}

The previous section dealt with the dialectic between hostility and hospitality. 
It discussed the need to move from one to the other: Especially since the resemble two sides of the same coin. In the presence of newcomers or immigrants, there are often two reactions: hostility or hospitality. When one rejects the former and chooses the latter reaction, one fits into the framework of morally approved actions guided by a cognisance of the humanity in the other as the replication of humanity present in oneself.

Consequently, hospitality as ethics of the encounter with the other must necessarily imply an ethics of responsibility. I would like to situate this ethics of responsibility within the framework of the now popular African proverb that proclaims: 'it takes a village to raise a child'.

A number of African cultures carry this proverb stressing social norms of collaboration and cooperation, the sense of community and the importance of the education of children in society (Owomoyela 2002; Sobania 2003; Mukenge 2002). In general, this proverb means that the education of a child is not limited to one's own parents; it extends and depends in part on his/her immediate surroundings. This means that even though parents play a leading role in the lives of their children, they are not the only ones who play a decisive role in the success of their children's lives and in their development as responsible people in society. Adults who surround them and meet them, i.e. the extended family (grandparents, uncles, aunts, and other relatives ...), friends, neighbors, educators, and society in general, each at various levels, also have a direct impact on children's lives (Cowen-Fletcher, et al. 1994).

Nevertheless, for the sake of this article, I present here a personal reinterpretation of this proverb in the context of the ethics of responsibility. Well beyond this consensual interpretation of the proverb, I understand that what Africans mean by this statement can also be referred to as the individual and collective responsibility towards a task of common interest. The proverb emphasizes such responsibility to collaborate and cooperate in matters of great importance for the building of society, which is likened to the raising of a child. The above-mentioned role is symbolic of any other duty that can only be met through the unity of all the forces. For example, to raise a child and to accompany him/ her on the journey of life and transform him/her into a resourceful person in the society, demands the collaboration and the cooperation of the whole village, of the whole society. As an ethics, this integrated responsibility is to be extended to all other places where the 'raising of a child' takes place; the whole village then bears some responsibility for the task.

From the foregoing, it is necessary to deliberate on the conceptual 
meaning of a village which is now assigned to our planet. Has it not been proclaimed that our planet has become a global village? (Bhavnagri 2001). The advancement of technologies in communications, and the acceleration of migrations can account for the construct of the global village. While attesting to the existence of this global community, many others question if the global village is long dead or if it is still alive. (Browne \& Marshall 1998). Such questioning is not surprising when one observes the exaltation of individualism throughout the world; the enthronement of racism, the praise of culturalism, the hardening of religiosity, the exaltation of nationalism and regionalism. Others have estimated that the concept of a global village is simply a myth (Metz 2015).

As evidenced by this short synopsis, the concept of a global village is under question. For example, while in Africa, the proverb, 'it takes a whole village to raise a child' is still meaningful, in Europe and many other places, it is rather the proverb 'sweep in front of your door' that seems appropriate (Von Goethe, N.D.). Though still bearing a call to responsibility, however such saying may be indicative of attitudes and behaviors of individuality, closedness and hostility towards issues that do not directly concern the individual, such might be the case with the problems of migrations.

Paradoxically, when some strive to close on themselves, within the borders of their nations that they attempt to consolidate and protect exclusively, it is clear that the global nature of information and communications, exchanges and interchangeability on several levels of life, cannot prevent participating in actions in the global community. There is therefore a requirement of coresponsibility to raise children and young people of migrations, regardless of where they come from because they are the children and young people of our global village, and it should take the whole village to raise them. In this endeavor, the ethics of responsibility can be unpacked in the following different layers.

\section{The Humanity in Children and Youth Migrants}

As suggested by the famous African proverb, 'it takes a village to raise a child', the ethics of responsibility requires parents, and the extended family members, to care for the children and young migrants who find themselves within the confines of the world's borders. This is because of the common humanity between migrants and others. It would be ethically inadmissible not to 
consider, respect and especially protect humanity in the other. This is one of the Categorical Imperatives of Immanuel Kant (Korsgaard,1986). In Kantian practical philosophy, humanity is an end in itself, and therefore it must be respected, considered and protected in oneself and in the other. All the more, because of this idea, the humanity in immigrants is a humanity open to multiple vulnerabilities, a humanity at risk and in danger, a humanity in need, it is therefore the ethics of responsibility as a mode of action required of each individual, a specific action towards this reduced humanity. According to Kant, 'the absolute value of humanity limits the way we can be treated by others and ourselves' (Altman 2011: 11). To formulate this more positively, I would say, the absolute value of humanity imposes an ethical way we can be treated by others and ourselves, and therefore imposes the same ethical way to treat the other (migrant).

When considering the best ways of treating humanity, of children and young migrants in particular, instead of sending them to concentration camps, temporary or permanent prisons, it would be better to include them in specialised programs. These would facilitate their cultural and social integration, their acceptance into existing structures of sociality and possibly to be granted citizenship so that they may use their newfound opportunities for the greater good of humanity. In integrating children and youth into its social structures, society can rejuvenate and help itself take care of its ageing members.

\section{Children and youth Migrants as a Possible Solution to the Population Ageing in Receiving Countries}

A finding of fact establishes the rise of an ageing population in most of the Western, North American and Asian countries (United Nations 2000). These countries also seem to be the most coveted countries for migration from the most troubled parts of the world. The ageing of human capital can be partly due to culture and very strict family policies. While I do not intend to argue in favor or against family policies that contribute to the ageing of populations, I will not stop myself from seeing the challenges that this phenomenon provokes. Population ageing presents enormous challenges not only to those countries directly concerned, but also to the entire humanity as there emerge difficulties to rejuvenate. This creates a deceleration of economic growth. Therefore, in the same way that global warming is a challenge for all humanity, the increasing ageing of human capital is also, in my opinion, a great challenge 
at the global level. This is because it somehow affects the entire humanity considering the types of challenges faced. A probable solution to balancing the ageing population could be the acceptance and integration of migrant youth and children from many other troubled parts of the world.

In the absence of such tentative solutions, challenges of the ageing population continue to increase, affecting different areas of life: the social, economic, cultural or political, and affecting the rest of the world at many levels (Sokolovsky 2009). In the face of demographic ageing, the economic challenge is added cruelly. The more populations are ageing, the more retirees there are, the fewer people are active enough to work, and the more countries spend on social services related to the maintenance of older citizens through pensions. It follows that since there are fewer workers, production declines and exports fall, resulting in the weakening of economies. The solution by some countries to raise the legal retirement age is an intermediate remedy, but not an effective solution in the long term (European Social Policy 2011). Others contend that,

although immigration may slow down this aging, it would not succeed in neutralizing this process unless it is massive in scale, making it economically, politically and socially unfeasible (Population Reference Bureau 2005).

This is largely the argument defended by conservatives, and the far-right extremists, obsessed with demographic conservatism, defending a blind nationalism, and imagining that migration is dangerous, especially since the newcomers will supposedly outnumber the 'true nationals'.

With this, more and more we see expressing and developing attitudes and actions of rejection towards the migrants. Against such an approach, I reiterate and reaffirm the intelligence and foresight of the United Nations which on $17^{\text {th }}$ March 2000 advocated a replacement migration strategy, especially in countries most affected by the phenomenon of demographic ageing:

According to United Nations forecasts, over the next 50 years, the population of virtually every country in Europe, as well as Japan, will face a declining population and aging. The new challenges posed by the decline and aging of the population will require a comprehensive 
reassessment of many established programs and policies, including those related to international migration. The report examines replacement migration in eight low-fertility countries (France, Germany, Italy, Japan, the Republic of Korea, the Russian Federation, the United Kingdom and the United States) and two regions (Europe and Central America) and European Union) (United Nations 2000).

A vocal critic of this resolution, Mickael Zhekoo (2018), suggests that it is unrealistic in the absence of progressive political and social policies of industrialised countries. While I disagree with this view, on the aspect of it being unrealistic, I am of the opinion that the replacement migration can provide a lasting solution to both sending and receiving countries. I further suggest that the term, 'Replacement' be changed to expressions such as: Addition Migration; Reinforcement Migration; Distributive Migration; or Hospitality Migration. Instead of 'replacement', migration can serve to add to the existing population, to redistribute the population where the need is most relevant in the form of the workforce. It is relevant to observe that, other critics denounced such migration of workforce, pointing out that through such migrations, on the one hand, industrialised countries,

... seek to end the spontaneous movement of undocumented people. On the other, they seek to channel migration into programs that would deliver migrants to industry as a contracted workforce ..., while at the same time restricting the ability of migrants to travel freely and decide for themselves where and when to live and work (Bacon 2008: 243).

Although it may appear that supporting workers' immigration is tantamount to imposing control over the movement of undocumented migrants, I support immigration by work contract as it gives immigrants the opportunity to find employment. However, it will be necessary to do more, not just to use immigrants as an easy and cheap labor force, but essentially as a valued addition to the work forces, and migrants should not be prevented from choosing to go elsewhere. Because if employers held them back by force, such restrictions may violate various ethical and legal precepts. To this effect, it is imperative to resonate the ethics of responsibility regarding the equitable redistribution of the population and there must equally resonate a new legal framework that protects the rights to migration. 


\section{To Secure and Perpetuate the Right to Migration}

Against the backdrop of migration restrictions, during a summit in Morocco, nations of the world postulated the absolute importance of another human right: the right to migration. Under the direction of the United Nations, a 'Global Compact for Safe, Orderly and Regular Migration' was agreed upon by several member states of the UN (Mamou 2018). This global pact does not deal with refugees who fall under the Geneva Convention, but concerns any other category of migrants. It stipulates that the migratory act is an individual 'choice' (as opposed to a 'necessity'), a choice that it is necessary to accompany, secure and perpetuate (2018). In previous sections, circumstances were highlighted in which people decided or were forced to migrate. It is therefore the ethical and legal responsibility of each sending and receiving country to secure and perpetuate this right. Only under reserved circumstances should such right be overruled by a state.

Another field of interest to be covered is the legal framework, that can encompass all existing international laws on migration with the aim to harmonise their applicability in various approaches. It should be noted that,

International migration law is based on three levels of norms, respectively, in customary law, treaty law and soft law. While mutually reinforcing, each focuses on a particular aspect of the migration and performs a specific function (Chetail 2017: 202).

Such laws would stipulate mechanisms for the distribution and reception of migrants throughout the world in such a way that well-defined quotas would be imposed on all industrialised countries, which should receive a certain number of migrants each year. United Nations migration agencies would be responsible for establishing reliable lists of possible migrants; and facilitate their departure within reasonable time. This will have the advantage of channelling, ordering and harmonizing migrations, and thus blocking the way for human traffickers. An international tribunal can be established to deal with cases of countries that do not abide by the international regulations on migration. All this is necessary in the effort to protect and promote the right to migration.

\section{Conclusion}

It has been contended in this reflection that migration is a global fact that has 
occurred since humanity existed. As a result, the debate on migration also becomes a global phenomenon. However, it has been argued that even if this phenomenon is global, the attention which it is given and the solutions provided so far often do not equate to the urgencies of interventions made in the cases of other phenomena of global interest, such as climate change. In this context, this reflection has articulated an argumentation to make the debate on migration a phenomenon of global interest, and that the solutions provided are also globally conceived in the context of a framework of ethical responsibility. The ethical framework of this responsibility is to be understood to the extent that a certain conduct designed to achieve wellbeing is always to be observed individually and collectively in the face of migrant children and youth. Every citizen in the world, and all member states of our planet bear the ethical responsibility to help raise children and young migrants, regardless of the place from which they originate. As a result, the policy of rejection, compulsory arrest, and progressive repatriation to home countries will have to shift to an alternative of educational, cultural and social reinsertion of children and young people, because it takes a whole village to raise a child.

\section{References}

Adepoju, A. 2000. Regional Integration, Continuity and Changing Patterns of Intra-regional Migration in Sub-Saharan Africa. International Migration into the $21^{\text {st }}$ Century. Essays in Honor of Reginald Appleyard. Aldershot: Eduard Elgar.

Afzal, B. 2007. Global Warming: A Public Health Concern. OJIN: The Online Journal of Issues in Nursing 12,2: 3.

Aihiokhai, S.A. 2017. An African Ethic of Hospitality for the Global Church:

A Response to the Culture of Exploitation and Violence in Africa Filosofia Theoretica: Journal of African Philosophy, Culture and Religions 6,2: $20-41$. https://doi.org/10.4314/ft.v6i2.2

Alaoui, H. 2019. The Lure of Authoritarianism: The Maghreb after the Arab Spring. Indiana University Press.

Altman, M.C. 2011. Kant and Applied Ethics: The Uses and Limits of Kant's Practical Philosophy. New York: John Wiley \& Sons.

https://doi.org/10.1002/9781118114162

Bacon, D. 2008. Illegal People: How Globalization Creates Migration and 
Criminalizes Immigrants. Beacon Press.

Baker, J., \& T.A. Aina (eds.). 1995. The Migration Experience in Africa. Uppsala: Nordic Africa Institute.

Bhavnagri, N.P. 2001. The Global Village: Migration and Education. Childhood Education 77,5: 256 - 259.

https://doi.org/10.1080/00094056.2001.10521647

Braasch, G. 2009. Earth under Fire: How Global Warming is Changing the World. University of California Press.

https://doi.org/10.1525/9780520943933

Browne, R.B. \& M.W. Fishwick 1998. The Global Village: Dead or Alive? Bowling Green: Bowling Green University Popular Press.

Bulley, D. 2015. Ethics, Power and Space: International Hospitality beyond Derrida. Hospitality \& Society 5,2-3: 185 - 201.

https://doi.org/10.1386/hosp.5.2-3.185_1

Casey, E.S. 2011. Strangers at the Edge of Hospitality. Phenomenologies of the Stranger: Between Hostility and Hospitality. New York: Oxford \& Fordham University Press.

https://doi.org/10.5422/fordham/9780823234615.001.0001

Chetail, V. 2017. November. Conceptualizing International Migration Law. In Proceedings of the One Hundred and Tenth Annual Meeting of the American Society of International Law: Charting New Frontiers in International Law. 31 March - 02 April 2016, Washington DC.

Cowen-Fletcher, J., J. Melia, R. DeRosa \& S. Blane 1994. It Takes a Village. New York, NY: Scholastic.

Creswell, J.W. \& C.N. Poth 2016. Qualitative Inquiry and Research Design: Choosing among Five Approaches. London: Sage publications.

Crush, J. 2001. The Dark Side of Democracy: Migration, Xenophobia and Human Rights in South Africa. International Migration 38,6: 103 - 133. https://doi.org/10.1111/1468-2435.00145

De La Baume, M. 2017. Angela Merkel Defends Open Border Migration

Policy. Available at: https://www.politico.eu/article/angela-merkeldefends-open-border-migration-refugee-policy-germany/

(Accessed on 12 December 2019.)

Derrida, J. 2000. Hospitality. Stocker, B. \& F. Morlock (trans.). Angelaki: Journal of the Theoretical Humanities 5,3: 3 - 16. (Accessed on 03 July 2019.)

Gibney, M. 1988. Open Borders? Closed Societies: The Ethical and Political 
Issues. Santa Barbara: Praeger Publishers.

European Social Policy 2011. Employment Council: Consensus on Need to

Raise Retirement Age. 7 April 2011. Available at:

https://www.questia.com/read/1G1-253903682/employment-council-

consensus-on-need-to-raise-retirement (Accessed on 16 July 2019.)

Flahaux, M.L. \& H. de Haas 2016. African Migration: Trends: Patterns,

Drivers. Comparative Migration Studies 4,1: 1-25.

https://doi.org/10.1186/s40878-015-0015-6 PMCid:PMC4909155

Helliwell, J.F. 2000. How Much do National Borders Matter? Washington

D.C.: Brookings Institution Press.

Kane, A. \& T.H. Leedy (eds.). 2013. African Migrations: Patterns and Perspectives. Indiana University Press.

Kearney, R. \& K. Semonovitch (eds.). 2011. Phenomenologies of the Stranger:

Between Hostility and Hospitality. New York: Oxford and Fordham University Press.

https://doi.org/10.5422/fordham/9780823234615.001.0001

Korsgaard, C.M. 1986. Kant's Formula of Humanity. Kant Studien 77,1-4: 83

-202. https://doi.org/10.1515/kant.1986.77.1-4.183

Kukathas, C. 2010. Expatriatism: The Theory and Practice of Open Borders.

Pennsylvania: State University Press.

Lemarchand, R. 2009. The Dynamics of Violence in Central Africa. Philadelphia: University of Pennsylvania Press.

https://doi.org/10.9783/9780812202595

Levinas, E. 1987. Time and the Other. Cohen, R.A. (trans.). Pittsburgh:

Duquesne University Press.

Lindberg, D.L. K. Razaki 2012. Conflict Minerals Disclosures: A Mandate of the Dodd-Frank Act. Journal of Business and Accounting 5,1:15 - 24.

Metz, S. 2015. The Global Village Myth: Distance, War, and the Limits of

Power. Parameters 45,2: 115 - 117.

Mukenge, T. 2002. Culture and Customs of the Congo-Culture and Customs of Africa. London: Westport.

Naido, S. 2003. The War Economy in the Democratic Republic of Congo. South Africa, Institute for Global Dialogue. Occasional Paper No 37. Available at:

http://www.igd.org.za/jdownloads/Occasional\%20Papers/op_37_chapter 1.pdf (Accessed on 12 December 2019.)

Nussbaum, B. 2003. Ubuntu: Reflections of a South African on our Common 
Humanity. Reflections: The SoL Journal 4,4: 21 - 26.

https://doi.org/10.1162/152417303322004175

Owomoyela, O. 2002. Culture and Customs of Zimbabwe. New York: Greenwood Publishing Group.

Population Reference Bureau 2005. The Aging of the Population Presents

Challenges for all Countries.

https://www.prb.org/levieillissementdelapopulation/

Rand, D.H. 2013. Roots of the Arab Spring: Contested Authority and Political

Change in the Middle East. New York: University of Pennsylvania Press. https://doi.org/10.9783/9780812208412

Shutte, A. 2009. Ubuntu as the African Ethical Vision. In Murove, M.F. (ed.): African Ethics. An Anthology of Comparative and Applied Ethics. Pietermaritzburg, University of Kwazulu-Natal Press.

Smith, R.M. ed. 2011. Citizenship, Borders, and Human Needs. New York: University of Pennsylvania Press.

https://doi.org/10.9783/9780812204667

Sobania, N.W. 2003. Culture and Customs of Kenya. New York: Greenwood Publishing Group.

Sokolovsky, J. (ed.) 2009. The Cultural Context of Aging: Worldwide Perspectives. Santa Barbara: ABC-CLIO.

Toro-Morn, M.I. \& M. Alicea (eds.) 2004. Migration and Immigration: A Global View. New York: Greenwood Publishing Group.

Turner, T. 2007. The Congo Wars: Conflict, Myth and Reality. London: Zed Books. https://doi.org/10.5040/9781350223011

United Nations 2000, Alternative Migration: A Solution for Declining and Aging Populations?

https://www.un.org/en/development/desa/population/publications/ageing /replacement-migration.asp

United Nations 2019. UN Climate Change Summit 2019. Available from: https://www.un.org/en/climatechange/ (Accessed on 12 December 2019). Victor, D.G. 2011. The Collapse of the Kyoto Protocol and the Struggle to Slow Global Warming. Princeton: Princeton University Press.

https://doi.org/10.1515/9781400824069

von Goethe, J.W. Let Everyone Sweeps in Front his Own Door, and the Whole World will be Clean. Available at:

https://www.brainyquote.com/quotes/johann_wolfgang_von_goeth 133 $\underline{629}$ (Accessed on 12 December 2019.) 
Waldinger, M. \& S. Fankhauser 2015. Climate Change and Migration in Developing Countries: Evidence and Implications for PRISE Countries. UK \& Ottawa: Centre for Climate Change, Economics and Policy, and International Development Research Centre, Canada.

Walker, J.Z. 2017. The Katangese Gendarmes and War in Central Africa: Fighting their Way Home. Bloomington, Indiana: Indiana University Press.

https://doi.org/10.1080/02582473.2017.1392593

White, G. 2011. Climate Change and Migration: Security and Borders in a Warming World. Oxford: Oxford University Press.

https://doi.org/10.1093/acprof:oso/9780199794829.001.0001

Whelan, F. 1988. Citizenship and Freedom of Movement: An Open Admission Policy? In Gibney, M. (ed.): Open Borders? Closed Societies? The Ethical and Political Issues. New York: Praeger.

Wiredu, K. 1995. Custom and Morality: A Comparative Analysis of Some African and Western Conceptions of Morals. In Mosley, A.G. (ed.): African Philosophy: Selected Readings. Englewood Cliffs: Prentice Hall. Wiredu, K. \& K. Gyekye 1992. Person and Community. Washington, DC: Council for Research in Values and Philosophy.

Yves Mamou, Le Figaro 2018. The UN Pact on Migrants Encourages Immigration Instead of Framing it.

http://www.lefigaro.fr/vox/politique/2018/11/21/31001-

20181121ARTFIG00303--le-pacte-de-l-onu-sur-les-migrants-vaencourager-1-immigration-au-lieu-de-l-encadrer.php

Zhekoo, M. 2018. The UN wants a 'Replacement Migration' or Why the Invasion of Migrants Organized by the European Union.

http://www.informations-en-direct-france.com/2018/05/l-onu-veut-unemigration-de-remplacement-ou-pourquoi-l-invasion-de-migrantsorganisee-par-l-union-europeenne.html (Accessed on 20 May 2019.)

Dr. Muko Cyril Keba Lecturer Saint Bonaventure's University College Lusaka Zambia kebamuko@gmail.com 